\title{
EL CONCEPTO DE ÓRGANO JURISDICCIONAL NACIONAL: UNA NOCIÓN EN PERMANENTE REVISIÓN
}

\author{
PILAR CONCELLÓN FERNÁNDEZ ${ }^{1}$ \\ Universidad de Oviedo \\ concellonpilar@uniovi.es
}

Cómo citar/Citation

Concellón Fernández, P. (2020).

El concepto de órgano jurisdiccional nacional: una noción en permanente revisión. Revista de Derecho Comunitario Europeo, 66, 629-658.

doi: https://doi.org/10.18042/cepc/rdce.66.11

\section{Resumen}

El TJUE continúa perfilando los elementos de su concepto autónomo de órgano jurisdiccional nacional. La sentencia de 21 de enero de 2020 en el asunto Banco Santander profundiza en el criterio de la independencia como rasgo imprescindible para la atribución de competencia prejudicial y excluye a los tribunales económicos administrativos españoles, rectificando su posición anterior. En ella, el Tribunal proyecta sus desarrollos jurisprudenciales recientes relativos a la importancia de la independencia del poder judicial como garantía del Estado de derecho y vuelve a incidir en que la independencia es una garantía que se impone tanto para los tribunales de la Unión como para los tribunales nacionales. Con nuevas decisiones en perspectiva, el concepto de órgano jurisdiccional nacional sigue siendo una noción en constante revisión.

1 Profesora Ayudante Doctor de la Universidad de Oviedo. Miembro del Grupo de Investigación Consolidado de Derecho Europeo de la Universidad de Oviedo (EURODER-UNIOVI-IDI/2018/000187). El presente trabajo se adscribe al Proyecto de I+D. «Obstáculos a la movilidad de personas en los nuevos escenarios de la UE», Ref. DER 2017-86017-R. 


\section{Palabras clave}

Concepto de órgano jurisdiccional nacional; cuestión prejudicial; artículo 267 TFUE; independencia; Tribunal Económico Administrativo.

\section{THE CONCEPT OF NATIONAL COURT: A CONCEPT UNDER CONSTANT REVIEW}

\section{Abstract}

The concept of 'national court' remains a notion under constant review. The Court has stressed again that the independence of national courts and tribunal is essential to the proper working of the judicial cooperation system embodied by the preliminary ruling mechanism. In its judgment of 21 January 2020, the ECJ declared that the request for a preliminary ruling from the Tribunal Económico Administrativo Central is inadmissible. It is clear that the reasoning in the judgment of $21 \mathrm{March}$ 2000, Gabalfrisa is unsatisfactory: The TEAC does not satisfy the requirements of independence necessary to constitute it as 'a court or tribunal' for the purposes of Article 267 TFEU.

\section{Keywords}

Definition of court or tribunal; preliminary ruling; Article 267 TFEU; independence.

\section{LA NOTION DE JURIDICTION NATIONALE: UN CONCEPT EN CONSTANTE RÉVISION}

\section{Résumé}

La CJ continue à afficher le concept d'organe judiciaire national. La Cour a souligné à nouveau que l'indépendance des cours et tribunaux nationaux est essentielle au bon fonctionnement du système de coopération judiciaire qu'incarne le mécanisme de renvoi préjudiciel. Dans son arrêt du 21 janvier 2020, la CJ a déclaré irrecevable la demande de décision préjudicielle introduite par le Tribunal Económico Administrativo Central. Il est clair que la motivation de l'arrêt du 21 mars 2000, Gabalfrisa n'est pas satisfaisante: le TEAC ne satisfait pas les exigences d'indépendance nécessaires pour constituer un «cour ou tribunal» aux fins de l'article 267 TFUE.

\section{Mots clés}

Notion de juridiction nationale; renvoi préjudiciel; article 267 TFUE; indépendance. 


\section{SUMARIO}

I. INTRODUCCIÓN. II. LA INDEPENDENCIA: UN CRITERIO AL ALZA EN LA CONFIGURACIÓN DEL CONCEPTO DE ÓRGANO JURISDICCIONAL NACIONAL. III. EL DISCUTIBLE ENCAJE DE LOS TRIBUNALES ECONÓMICO ADMINISTRATIVOS ESPAÑOLES COMO ÓRGANOS JURISDICCIONALES. IV. LAS AGUAS VUELVEN A SU CAUCE: LA SENTENCIA DE 21 DE ENERO DE 2020 EN EL ASUNTO BANCO DE SANTANDER. V. LAS RAZONES DEL CAMBIO JURISPRUDENCIAL. VI. LA LETRA PEQUEÑA DEL ASUNTO BANCO SANTANDER: LOS ÓRGANOS DE NATURALEZA ADMINISTRATIVA. VII. EL PRÓXIMO ESCOLLO: LA COMISIÓN NACIONAL DE LOS MERCADOS Y LA COMPETENCIA. VIII. CONSIDERACIONES FINALES. BIBLIOGRAFIA.

\section{INTRODUCCIÓN}

Ante el silencio de los Tratados, el TJUE ha ido delimitando a partir de la conocida sentencia Vaasen Göbbels ${ }^{2}$ el concepto de órgano jurisdiccional nacional en el sentido del art. 267 TFUE mediante el enunciado de cierto número de criterios que debe satisfacer el órgano de que se trate, como son el origen legal del órgano, su permanencia, el carácter obligatorio de su jurisdicción, el carácter contradictorio del procedimiento y la aplicación por parte del órgano de normas jurídicas, así como su independencia e imparcialidad ${ }^{3}$. De este modo, tal como señalan Fenger y Broberg (2013: 86), «il est toutefois possible de déduire de la jurisprudence de la Cour de justice un certain nombre de critères organisationnels et fonctionnel pertinents pour déterminer si une entité peut introduire un renvoi préjudiciel sur la base de cette disposition $»^{4}$.

Sin embargo, aun cuando todos estos requisitos han sido confirmados por el TJ en pronunciamientos posteriores ${ }^{5}$, en la jurisprudencia también

2 Sentencia de 30 de junio 1966, C-61/65, EU:C:1966:39.

3 Este último criterio fue introducido ex novo en la sentencia Pretore di Saló (Sentencia de 11 de junio de 1987, C-14/86, EU:C:1987:275, apdo. 7); en la sentencia Vaasen Göbbels no se hacía ninguna referencia a la independencia del órgano jurisdiccional.

4 En este mismo sentido, Biavati (2005: 419-422); Condinanzi y Mastroianni (2009: 193-205); Fenger y Broberg (2013: 87-97); Lenaerts, Arts y Maselis (2014: 52-55); Simon (1998: 487-492).

5 Sentencia de 30 de noviembre de 2000, Österreichischer Gewerkschaftsbund, C-195/98, EU:C:2000:655; Sentencia de 29 de noviembre de 2001, De Coster, 
encontramos casos en los que el $\mathrm{TJ}$ ha examinado el carácter jurisdiccional del órgano remitente sin tener en cuenta alguno de estos rasgos o relajando su nivel de exigencia, siguiendo un criterio más «elástico y en realidad poco científico» (Ruiz-Jarabo Colomer, 1993: 71-82) ${ }^{6}$. En cambio, ha puesto el énfasis en otros criterios?

C-17/00, EU:C:2001:651; Sentencia de 15 de enero de 2002, Lutz y otros, C-182/00, EU:C:2002:19; Sentencia de 30 de marzo de 2006, Emanuel, C-259/04, EU:C:2006: 215; Sentencia de 23 de diciembre de 2009, CoNISMa ,C-305/08, EU:C:2009:807; Sentencia de 14 de junio de 2011, Miles y otros, C-196/09, EU:C:2011:388; Sentencia de 13 de diciembre de 2012, Forposta y ABC Direct Contact, C-465/11, EU:C:2012: 801; Sentencia de 31 de enero de 2013, Belov, C-394/11, EU:C:2013:48; Sentencia de 12 de junio de 2014, Ascendi Beiras Litoral e Alta, C-377/13, EU:C:2014:1754; Sentencia de 6 de octubre de 2015, Consorci Sanitari del Maresme, C-203/14, EU:C:2015:664. En todos ellos el TJ viene a repetir casi literalmente que «Para apreciar si el organismo remitente posee el carácter de un órgano jurisdiccional en el sentido del artículo 267 del TFUE, cuestión que pertenece únicamente al ámbito del Derecho comunitario, el Tribunal de Justicia tiene en cuenta un conjunto de elementos, como son el origen legal del órgano, su permanencia, el carácter obligatorio de su jurisdicción, el carácter contradictorio del procedimiento, la aplicación por parte del órgano de normas jurídicas, así como su independencia».

6 Para Cienfuegos Mateo (2014: 43) «la noción de órgano jurisdiccional constituye uno de los aspectos del incidente prejudicial que ha dado lugar a más intervenciones del Tribunal de Justicia, no siempre esclarecedoras ni convincentes, pues el análisis llevado a cabo de la jurisprudencia comunitaria (de)muestra una casuística poco ejemplificadora». En este mismo sentido véase Soca Torres (2016).

7 En ocasiones, el carácter contradictorio del procedimiento principal no ha sido condición de admisibilidad; el TJ ha dicho que "podría ser admitido un reenvío que se suscitara en un procedimiento no contradictorio o en una fase sin contradicción de un procedimiento que sí lo es». Así, en las sentencias Pretore di Centro, Protura Unificata di Torino o Pardini el TJ dio respuesta a cuestiones prejudiciales suscitadas en procedimientos que carecían de partes o decidían sobre la adopción de medidas cautelares. No obstante, en estos casos la falta de contradicción en el procedimiento se compensaba por la total independencia del órgano que planteaba la cuestión prejudicial (sentencias de 5 de mayo de 1977, C-110/76, EU:C:1977:75, de 22 de septiembre de 1988, C-228/87, EU:C:1988:442 y de 21 de abril de 1988, C-338/85, EU:C:1988:194, respectivamente). En cuanto al carácter jurisdiccional de la decisión que pone fin al proceso, hay que señalar que es, probablemente, la condición más confusa. Para determinar si una decisión tiene carácter jurisdiccional, el TJ ha utilizado dos criterios diferentes: unas veces ha tenido en cuenta la naturaleza "conflictual» del procedimiento en el que se adoptada la decisión y otras la pertenencia de su autor a la organización judicial (autos de 18 de junio de 1980, Borker, C-138/80, EU:C:1980:162 y de 5 de 
La doctrina ha intentado sistematizar el estado jurisprudencial de esta cuestión. Fenger y Broberg (2013: 98-99) apuntan que cuando el órgano remitente no pertenezca al poder judicial de un Estado miembro, el TJ dará mayor importancia a la independencia y obligatoriedad de su jurisdicción, restando importancia a la naturaleza contradictoria del procedimiento o a la aplicación por parte del órgano de normas jurídicas; por el contrario, cuando el TJ reciba una cuestión prejudicial de un órgano perteneciente al sistema jurisdiccional de un Estado miembro, el TJ tendrá principalmente en cuenta el carácter jurisdiccional de la resolución que ponga fin al procedimiento a quo. También precisan que aunque una autoridad esté incluida en la organización jurisdiccional de un Estado, no siempre actúa en el ejercicio de tales poderes ${ }^{8}$. En consecuencia, que una cuestión prejudicial proceda de un órgano perteneciente al poder judicial de un Estado miembro no evitará que el TJ evalúe el tipo de función que el órgano está desarrollando en el momento en que decide realizar el reenvío (Concellón Fernández, 2020: 41).

\section{LA INDEPENDENCIA: UN CRITERIO AL ALZA EN LA CONFIGURACIÓN DEL CONCEPTO DE ÓRGANO JURISDICCIONAL NACIONAL}

Aun cuando el TJ sigue sin proporcionarnos una definición unívoca de órgano jurisdiccional (Tridimas, 2003: 9-27) o una ponderación expresa de los diferentes requisitos (Oliver, 2001: 5-17), en los últimos años el criterio de la independencia ha ido adquiriendo una mayor relevancia. El TJ ha señalado

marzo de 1986, Greis Unterweger, C-318/15, EU:C:2016:747 y sentencias de 12 de noviembre de 1998, Victoria Film, C-134/97, EU:C:1998:535 y de 12 de diciembre de 1996, Procesos Penales contra X, C-74/95 y C-129/95, EU:C:1996:491, respectivamente).

8 Para Alonso García (2011: 154), «una cosa es el concepto de «órgano jurisdiccional» en sí mismo considerado, y otra el concreto contexto en el que intervenga». Tal como señalara Dámaso Ruiz-Jarabo en sus conclusiones para el asunto Roda Golf, a pesar de que la definición de órgano jurisdiccional esté íntimamente ligada a la de litigio, ambos aspectos son diferentes: "Aunque una autoridad esté incluida en la organización jurisdiccional de un Estado, no siempre actúa en el ejercicio de tales poderes y por eso, el Tribunal de Justicia habría construido un motivo de admisión ligado a la naturaleza del órgano y otro para las tareas que acomete. En otras palabras, un órgano jurisdiccional, aunque ostente dicha naturaleza, no siempre ejerce jurisdicción. Son vertientes diversas que reciben un tratamiento distinto» (Conclusiones el abogado general Ruiz-Jarabo, Roda Golf \& Beach Resort SL, C-14/08, EU:C:2009:134, punto 51). 
que a los efectos del planteamiento de cuestiones prejudiciales, el que un «órgano» actúe de manera independiente implica, ante todo, que el órgano de que se trate tenga la cualidad de tercero en relación con la autoridad que haya adoptado la decisión recurrida, de manera que ha de estar protegido de injerencias o presiones externas que puedan hacer peligrar la independencia de sus miembros, al tiempo que debe guardar igualdad de distancias respecto a las partes del litigio y sus intereses?.

ElTJ ha ido desarrollando una «impresionante línea jurisprudencial relativa a las exigencias de la independencia judicial» ${ }^{10}$. Desde la sentencia Wilson ${ }^{11}$, el $\mathrm{TJ}$ ha venido insistiendo en que la noción de independencia comporta dos aspectos: un aspecto externo y otro interno. El primero implica que el órgano esté protegido contra esas injerencias o presiones externas que puedan poner en peligro la independencia de juicio de sus miembros en cuanto a los litigios que se les sometan. El segundo se aproxima más al concepto de imparcialidad y hace referencia a la equidistancia del órgano con respecto a las partes del litigio y a sus respectivos intereses en relación con el objeto de tal litigio ${ }^{12}$. Estas garantías

9 Entreotras:sentenciasde30 demayo de2002,Schmid,C-516/99, apdo.36;EU:C:2002: 313; de 19 de septiembre de 2006, Wilson, C-506/04, EU:C:2006:587, apdo. 49; de 22 de diciembre de 2010, RTL Belgium, C-517/09, EU:C:2010:821, apdo.38; de 31 de enero de 2013, D. Y A., C-175/11, EU:C:2013:45, apdo.95; de12 de junio de 2014, Ascendi Beiras Litoral e Alta, Auto Estardas Das Beiras Litoral e Alta, ya citada, apdo. 32; de 17 de julio de 2014, Torresi, C-58/13 y C-59/13, EU:C:2014:2088, apdo. 23; de 9 de octubre de 2014, TDC, C-222/13, EU:C:2014:2265, apdo.29 y de 6 de octubre de 2015, Consorci Sanitari del maresme, ya citada, apdo.19. Evidentemente, el concepto de la independencia judicial tiene también una dimensión estatal muy relevante en la que este trabajo no entra dado que el TJUE ha insistido en que la noción de «órgano jurisdiccional nacional» debe ser un concepto de contenido específicamente comunitario, no determinable por los Estados miembros; en todo caso, desde la perspectiva española y entre la bibliografía existente puede verse Martín Ríos (2020), Pérez Alonso (2018) y Sosa Wagner (2016).

10 Conclusiones del abogado general Hogan, Banco Santander, C-274/14, EU:C:2019: 802 , punto 5 .

11 Sentencia de 19 de septiembre de 2006, ya citada.

12 Sentencias de 19 de septiembre de 2006, Wilson, ya citada, apdos. 49-53; de 22 de diciembre de 2010, RTL Belgium, ya citada, apdos. 39-40; de 31 de enero de 2013, D. Y A., ya citada, apdos. 96-97; de 17 de julio de 2014, Torresi, ya citada, apdo. 18; de 9 de octubre de 2014, TDC, ya citada, apdos. 30-31 y de 6 de octubre de 2015, Consorci Sanitari del maresme, ya citada, apdo. 19 y Auto de 14 de mayo de 2008, Pilato, C-109/07, EU:C:2008:274, apdo. 23. El asunto Margarit Panicello resulta especialmente ilustrativo para entender esta doble vertiente. El TJ consideró que los secretarios judiciales cumplían plenamente con el aspecto interno de la independen- 
de independencia e imparcialidad demandan la existencia de reglas específicas, especialmente en lo referente a la composición del órgano, así como al nombramiento, a la duración del mandato y a las causas de inhibición, recusación y cese de sus miembros, que permitan excluir toda duda legítima en el ánimo de los justiciables en lo que respecta a la impermeabilidad de dicho órgano frente a elementos externos y en lo que respecta a su neutralidad con respecto a los intereses en litigio ${ }^{13}$. De modo que para considerar cumplido el requisito relativo a la independencia del órgano de remisión, la jurisprudencia exige, en particular, que los supuestos de cese de los miembros de ese órgano estén previstos en disposiciones legales expresas ${ }^{14}$.

\section{EL DISCUTIBLE ENCAJE DE LOS TRIBUNALES ECONÓMICO ADMINISTRATIVOS ESPAÑOLES COMO ÓRGANOS JURISDICCIONALES}

La consideración como órgano jurisdiccional nacional de los tribunales económico administrativos españoles ha sido una de las cuestiones más debatidas en relación al concepto de órgano jurisdiccional desde la perspectiva de la independencia. Desde que en la década de los noventa el TJ respondiera a la primera cuestión prejudicial planteada por uno de ellos, las críticas se han sucedido hasta el punto de que los asuntos Diversinte ${ }^{15}$ y Gabalfrisa ${ }^{16}$ se han tornado en paradigmas de la dependencia orgánica y funcional ${ }^{17}$.

cia y desempeñaban sus funciones con plena observancia de la imparcialidad y de la objetividad en relación con las partes y con los intereses de estas en el ligio, actuando, por tanto, como terceros. Sin embargo, no llegó a la misma conclusión respecto a la dimensión externa. El TJ consideró que los letrados de la administración de justicia, en el ejercicio de sus funciones, debían atenerse a las instrucciones que les impartiera su superior jerárquico salvo cuando ejercían las competencias relativas a la fe pública judicial (Concellón Fernández, 2017: 709-733).

13 Sentencia Wilson, ya citada, apdo. 53.

14 Sentencia de 31 de enero de 2013, D. y A., ya citada, apdo. 97, y auto de 14 de mayo de 2008, Pilato, ya citado, apdo. 24.

15 Sentencia del Tribunal de Justicia de 1 de abril de 1993, Diversinte y Iberlacta, C-260/91 y C-261/91, EU:C:1993:136.

16 Sentencia de 21 de marzo de 2000, Gabalfrisayotros, C-110/98 a C-147/98, EU:C:2000:145.

17 Algunos órganos remitentes se han servido de la admisión de las cuestiones prejudiciales remitidas por los TEA españoles para justificar su competencia prejudicial. A modo de ejemplo, en su Decreto de 17 de septiembre de 2015, el letrado de la Administración 
En 1990 el Tribunal Económico Administrativo Central (TEAC), a través de su resolución de 29 de marzo de 1990 y en base a los criterios enumerados en la jurisprudencia del TJ, se autoproclamó competente para realizar reenvíos prejudiciales. Un año después, y en coherencia a lo declarado en su resolución, el mismo TEAC planteó dos cuestiones prejudiciales que dieron lugar al asunto Diversinte, en el que ni el abogado general ni la propia sentencia del Tribunal de Justicia pusieron en duda la legitimación del TEAC para plantear cuestiones prejudiciales. Reconocieron implícitamente su carácter jurisdiccional y avalaron, por tanto, en contra de la opinión de la mayor parte de la doctrina, su autoproclamación como órgano jurisdiccional a los efectos del actual art. $267 \mathrm{TFUE}^{18}$.

Años después de este asunto, mediante varias resoluciones recibidas en el Tribunal de Justicia el 14 de abril de 1998, el Tribunal Económico Administrativo Regional de Cataluña planteó una cuestión prejudicial relativa a la interpretación de la Sexta Directiva en materia de armonización de las legislaciones de los Estados miembros relativas a los impuestos sobre el volumen de negocios. En esta ocasión, el TJ sí consideró necesario valorar si el órgano remitente era efectivamente un órgano jurisdiccional. En su sentencia de 21 de marzo de $2000^{19}$, el TJ concluyó que la legislación española ${ }^{20}$ garantizaba la separación funcional entre los servicios de la Administración Tributaria responsables de la gestión, liquidación y recaudación, por una parte, y, por otra, de los tribunales económico administrativos, que resuelven las reclamaciones presentadas contra las decisiones de dichos servicios, lo que bastaba para conferirles «la cualidad de tercero en relación con los servicios que adoptaron la decisión objeto de la reclamación y la independencia necesaria para poder ser considerados órganos jurisdiccionales en el sentido del artículo 177 del Tratado $»^{21}$.

Ello a pesar de que en sus conclusiones el abogado general Saggio hubiese dejado patente que procedía albergar serias dudas sobre la independencia y el carácter contradictorio del procedimiento. Saggio había alertado de que los

española que planteó el asunto Margarit Panicello se valía de la sentencia Gabalfrisa para fundamentar su independencia y con ello su competencia jurisdiccional.

Sentencia del Tribunal de Justicia de 1 de abril de 1993, ya citada, y Conclusiones del abogado general Gulmann, presentadas el 3 de diciembre de 1992, Diversinte y Iberlacta, C-260/91 y C-261/91, EU:C:1992:493.

Mediante varias resoluciones recibidas en el TJ el 14 de abril de 1998, el Tribunal Económico Administrativo Regional de Cataluña planteó una cuestión prejudicial relativa a la interpretación de la Sexta Directiva en materia de armonización de las legislaciones de los Estados miembros relativas a los impuestos sobre el volumen de negocios.

Se trataba del art. 90 de la Ley 230/1963, de 28 de diciembre, General Tributaria. Apdo. 40 de la sentencia. 
tribunales económico administrativos estaban integrados orgánicamente en el Ministerio de Economía y Hacienda y de que el propio ministro tenía la facultad de destituir a los miembros de los tribunales económico administrativos sin ningún límite claro "taxativamente previsto por la ley» ${ }^{22}$.

Desde luego, la falta de independencia de los TEA, en su vertiente interna, era un hecho contrastado ${ }^{23}$ : la facultad del Consejo de Ministros de nombrar a sus miembros se extiende también al poder de separarlos; su cese solo necesita de la publicación de un real decreto en el Boletín Oficial del Estado.

Saggio también había señalado que de las disposiciones que regulaban la composición y el funcionamiento de los TEAR no podía concluirse que los tribunales económico administrativos actuaran «con todas las garantías de independencia y de posición de tercero con respecto al poder ejecutivo», ya que el hecho de estar integrado orgánicamente en el Ministerio de Economía y Hacienda y que sus resoluciones fueran recurribles en todos los casos ante los órganos de la jurisdicción contencioso administrativa demostraban que la reclamación económico-administrativa ejercía la función típica de los recursos administrativos: "Dar a la Administración la oportunidad de dictar, también mediante un procedimiento contradictorio con los interesados, su decisión en justicia definitiva $»^{24}$.

La doctrina llevaba años alertando de que el reconocimiento de competencia prejudicial a los TEA supondría atribuirles una naturaleza jurídica que no les correspondía. Alonso García consideraba que el TJ debía inadmitir las cuestiones prejudiciales remitidas por este tipo de órganos «sólo por el hecho de tratarse de órganos dotados legalmente, que no constitucionalmente, de funciones para-judiciales, cuyas resoluciones, además, sí serían susceptibles

22 El abogado general Saggio señaló asimismo que las resoluciones de los TEAR eran recurribles en todos los casos ante los órganos de la jurisdicción contencioso administrativa, lo cual demostraba que la reclamación económico-administrativa ejercía la función típica de los recursos administrativos: «Dar a la Administración la oportunidad de dictar, también mediante un procedimiento contradictorio con los interesados, su decisión en justicia definitiva» (Conclusiones del abogado general Saggio, Gabalfrisa, C-110/98, EU:C:1999:489, punto 18).

23 Recordemos que desde la década de los noventa la mayor parte de la doctrina especializada ha cuestionado que los tribunales económico-administrativos estuvieran dotados de la independencia necesaria para ser calificados como órganos jurisdiccionales a los efectos del art. 267 TFUE (Alonso García, 2011: 147-166; Banacloche Pérez-Roldán, 2001: 83-90; Cienfuegos Mateos, 2005: 3-26; García de Enterría, 1986: 707; Ruiz-Jarabo Colomer, 1993: 80-82; Soriano García, 1989).

24 Conclusiones del abogado general Saggio, ya citadas, punto 18. 
de revisión por auténticos tribunales integrados en el poder judicial» (Alonso García, 2011: 156; Banacloche Pérez-Roldán, 2001: 1-8).

Dentro del propio poder judicial español, el Tribunal Supremo y la Audiencia Nacional también habían cuestionado el carácter jurisdiccional de los tribunales económico administrativos. En sus sentencias de 4 de enero de 1980 y de 28 de enero de $2002^{25}$, el Tribunal Supremo señaló que los tribunales económicos administrativos eran órganos administrativos, no de gestión sino de resolución de reclamaciones: órganos especializados dentro de la propia Administración. Por su parte, en la sentencia de 25 de noviembre de $2010^{26}$, la Audiencia Nacional rechazó de manera rotunda el carácter de órgano jurisdiccional del TEAR de Asturias. En síntesis, la Audiencia Nacional consideró que pese a que en alguna ocasión aislada se hubiese reconocido a los tribunales económico administrativos legitimación para el planteamiento de cuestiones prejudiciales ante el TJ, ello era debido probablemente a la confusión a la que inducía su denominación y su pretendido estatuto de autonomía funcional. Para la Audiencia Nacional, no podía admitirse que los tribunales económico administrativos, incardinados en el seno de la Administración del Estado, pudieran ser equiparados, ni siquiera de modo analógico, a los órganos jurisdiccionales, ya que no podrían dispensar como estos la tutela judicial efectiva a que se refiere el art. 24 de la CE. Tampoco los funcionarios que los componen, "por probos que fueran», serían según su criterio «equiparables de ninguna manera a los jueces y magistrados, cuyo estatuto constitucional queda establecido en el art. 117 CE» (Ibáñez García, 2011).

En definitiva, aunque el TJ no se rija por un sistema estricto de precedentes, resulta evidente que las consideraciones formuladas en la sentencia Gabalfrisa y otros no resultaban satisfactorias y en consecuencia no debían seguir sirviendo como referencia para el examen de la competencia prejudicial ${ }^{27}$.

\section{LAS AGUAS VUELVEN A SU CAUCE: LA SENTENCIA DE 21 DE ENERO DE 2020 EN EL ASUNTO BANCO DE SANTANDER}

El asunto Banco Santander ${ }^{28}$ ha permitido al TJ volver a poner las cosas en su sitio. La cuestión se plantea en el transcurso de un recurso interpuesto

25 RJ 198013 y RJ 20021899.

26 JT 2010/1227.

27 Así concluye el abogado general Hogan en sus conclusiones para el asunto Banco Santander (conclusiones del abogado general Hogan, ya citadas, punto 43).

28 Sentencia de 21 de enero de 2020, C-274/14, EU:C:2020:17. 
ante el TEAC por el Banco de Santander contra un acuerdo de liquidación realizado por la Inspección de la Hacienda española ${ }^{29}$. El litigio, retomado a principios de 2019, permanecía suspendido desde el planteamiento inicial de la petición de decisión prejudicial en $2014^{30}$, debido a la existencia de otros muchos procedimientos en los que se habían impugnado la legalidad de la Decisión 2011/5 y de la Decisión 2015/314 ante el Tribunal General y el Tribunal de Justicia ${ }^{31}$. Sin embargo, después de que la Comisión expresara sus dudas acerca de la independencia de los tribunales económico-administrativos $^{32}$, mediante resolución de 30 de abril de 2019, el TJ decidió que en primer lugar procedía examinar su propia competencia para responder a las cuestiones prejudiciales del TEAC.

29 Dicha liquidación se llevó a cabo tras la adquisición por Banco de Santander, en mayo de 2002, del $100 \%$ de las acciones de una sociedad alemana, AKB, por la suma de 1099999999 euros. Unos seis meses después, Banco de Santander transmitió las acciones de AKB a dos sociedades de su grupo. Finalmente, Banco de Santander consideró que el fondo de comercio financiero asociado a dicha operación podía ser amortizado conforme a las ventajas fiscales previstas en la legislación tributaria española. Tras el recurso interpuesto por el Banco Santander, el TEAC planteó tres cuestiones prejudiciales, una de interpretación, sobre la Decisión 2011/5/CE de la Comisión, de 28 de octubre de 2009, y dos de validez, sobre la decisión de la Comisión de incoar un procedimiento conforme al art. 108 TFUE, apdo. 2, en relación con la Ayuda estatal SA.35550 (13/C) y sobre la Decisión de la Comisión (UE) 2015/314, de 15 de octubre de 2014, relativa a la Ayuda estatal SA.35550 (13/C).

30 Desde entonces el TEAC ha reformulado sus cuestiones en dos ocasiones. La primera en enero de 2015 y la segunda en junio de 2017.

31 Sobre todo, en el asunto que dio lugar a la Sentencia de 21 de diciembre de 2016, Comisión/World Duty Free Group y otros (C-20/15 P y C-21/15 P, EU:C:2016:981). Razón por la que el abogado general Hogan considera innecesario entrar a examinar con detalle el fondo de la petición de decisión prejudicial: «Solo hay un objeto de debate ante el Tribunal de Justicia: si el TEAC es un «órgano jurisdiccional» a efectos del artículo 267 TFUE» (punto 11 de las conclusiones).

32 En su escrito de alegaciones la Comisión sugiere que los tribunales económico administrativos sean excluidos del concepto de órgano jurisdiccional contenido en el art. 267 TFUE y que, en consecuencia, el Tribunal se declare incompetente para pronunciarse sobre las cuestiones prejudiciales planteadas por el TEAC. Según expone la Comisión, no puede considerarse que el TEAC cumpla el requisito relativo a la independencia, tal como señala, la normativa española «se limita a prever, por un lado, que los tribunales económico administrativos "actuarán con independencia funcional en el ejercicio de sus competencias" y, por otro, que el presidente y los vocales del TEAC son nombrados y separados por real decreto del Consejo de Ministros, a propuesta del Ministro de Economía y Hacienda» (Escrito de alegaciones de 22 de septiembre de 2014, puntos 31-40). 
Tras remitir varias preguntas escritas a las $\operatorname{partes}^{33}$ y celebrarse la vista, sentencia y conclusiones parten de un mismo punto, la necesidad de dar respuesta a una interrogante común: "¿Sigue siendo válida la jurisprudencia Gabalfrisa, habida cuenta de la evolución de la jurisprudencia del Tribunal de Justicia desde que se dictó la sentencia?» ${ }^{34}$.

El TJ comienza su examen señalando que a la vista de los autos que obran ante él, no cabe duda de que los tribunales económico administrativos cumplen los criterios del origen legal, la permanencia, el carácter obligatorio de su jurisdicción, el carácter contradictorio del procedimiento y la aplicación por dicho organismo de normas jurídicas. No obstante, se plantea, en cambio, si el TEAC responde al criterio de independencia. A partir de ahí, el TJ centra su examen en comprobar si los TEA reúnen los dos aspectos que comportan el concepto de independencia: el externo y el interno.

En primer lugar, respecto al criterio externo, el TJ considera acreditado que la legislación española no garantiza que el presidente y los vocales del TEAC se encuentren al amparo de presiones externas, directas o indirectas, que puedan hacer dudar de su independencia. En base a lo expuesto en la vista oral por el representante del Gobierno español, el TJ considera acreditado que los miembros del TEAC pueden ser apartados de sus funciones tal como fueron nombrados, esto es, por real decreto del Consejo de Ministros: «El régimen de separación de los miembros del TEAC no está previsto en una normativa específica, mediante disposiciones legales expresas como las aplicables a los miembros del poder judicial, [...] a los miembros del TEAC se les aplican únicamente las normas generales del Derecho administrativo $y$, en particular, el Estatuto Básico del Empleado Público» ${ }^{35}$.

El TJ advierte de que la separación del presidente y los vocales del TEAC y de los miembros de los demás TEA tampoco se limita, como exige el principio de inamovilidad, a ciertos supuestos excepcionales que reflejen motivos legítimos e imperiosos que justifiquen la adopción de tal medida y en

33 En sus observaciones escritas de 24 de septiembre de 2014, la Abogacía del Estado español señala que los TEA son órganos jurisdiccionales, sin embargo, evita calificarles como órganos independientes: «El órgano jurisdiccional remitente es un tribunal económico-administrativo conforme al Derecho español. Este tribunal es competente para plantear cuestiones prejudiciales, tal y como se estimó el Tribunal de Justicia en sentencia de 20 de marzo de 2000 . Tal y como se señala en la resolución de remisión, se trata de un tribunal con origen legal, carácter permanente y jurisdicción obligatoria. De igual modo, sus resoluciones se fundan en derecho en un procedimiento contradictorio".

34 Punto 14 de las conclusiones.

35 Apdo. 66 de la sentencia. 
los que se respete el principio de proporcionalidad y se observen los procedimientos establecidos al efecto, como pueden ser un supuesto de incapacidad o de falta grave que les impida reunir las condiciones de aptitud para continuar en el ejercicio de sus funciones ${ }^{36}$.

En la misma línea, el abogado general había estimado que los miembros del TEAC no tienen el necesario grado de permanencia en su cargo, «el solo hecho de que los miembros del TEAC hayan sido cesados mediante decreto-ley por motivos que parecen obedecer a la conveniencia del Gobierno de turno basta, por sí mismo, para demostrar que el TEAC carece de esta crucial característica» ${ }^{37}$. Los datos expuestos por la propia Comisión y el abogado general Hogan lo constatan ${ }^{38}$, en los últimos años la facultad de cese ha sido ejercida con frecuencia: «El 13 de enero de 2012 el presidente y un vocal del TEAC fueron cesados, y este último fue nombrado nuevo presidente del TEAC. De igual manera, el 1 de junio de 2018 el presidente del TEAC fue cesado y sustituido por otro. El 6 de julio de 2018, otros cuatro vocales del TEAC fueron destituidos y se confirmó en el cargo a otros ocho" ${ }^{39}$.

En segundo lugar, al abordar el aspecto interno de la independencia, el TJ centra su análisis en el recurso extraordinario para la unificación de la doctrina regulado en el art. 243 de la LGT. Al igual que lo hiciera Hogan, para quien el solo hecho de que determinados miembros de la sala especial del TEAC mantengan estrechos vínculos institucionales con la Administración Tributaria debe bastar para que se susciten dudas acerca de la independencia del TEAC ${ }^{40}$, el TJ advierte de que «algunas características del procedimiento de recurso extraordinario ante la Sala Especial para la Unificación de Doctrina regulado por el artículo 243 de la LGT contribuyen a poner en duda que el TEAC tenga la condición de tercero con respecto a los intereses en litigio» ${ }^{41}$.

En el asunto Gabalfrisa no se había entrado a examinar si las características del recurso para la unificación de la doctrina ponían en duda que los

36 Apdo. 67 de la sentencia.

37 Hogan añade que "para cumplir con este aspecto del requisito de independencia sería necesario que los miembros del TEAC disfrutasen de garantías reales y efectivas frente a la destitución, salvo causa justificada o incapacidad» (apdo. 38 de las conclusiones).

38 Punto 23 de las conclusiones.

39 Punto 24 de las conclusiones.

40 En palabras de Hogan: «un sujeto pasivo medio y razonable que haya presentado una reclamación ante el TEAC percibirá que [...] la peculiar composición de la sala especial prevista por la ley, parece desequilibrado por estar inclinado a favor de las autoridades tributarias» (punto 40 de las conclusiones).

41 Apdo. 73 de la sentencia. 
TEA tuvieran la condición de tercero con respecto a las partes del litigio; no obstante, según la normativa española, es el propio director general de tributos del Ministerio de Economía y Hacienda, miembro nato de la sala especial para la unificación de la doctrina, quien debe interponer el recurso contra las resoluciones del TEAC con las que esté en desacuerdo. Además, la sala especial está formada por otros siete miembros, entre los que se encuentra el director general o el director del departamento de la Agencia Estatal de Administración Tributaria del que dependa funcionalmente el órgano que hubiera dictado el acto a que se refiere la resolución objeto del recurso extraordinario ${ }^{42}$.

Para el TJ, las características del recurso extraordinario ponen de relieve los vínculos orgánicos y funcionales que existen entre el TEAC y el Ministerio de Economía y Hacienda, y en concreto entre el director general de tributos del Ministerio y el director general cuya dirección general hubiera dictado las resoluciones impugnadas ante él: «La existencia de tales vínculos se opone a que se le reconozca al TEAC la cualidad de tercero en relación con dicha Administración [...] Por lo tanto, el TEAC no cumple con la exigencia de independencia, en su aspecto interno ${ }^{43}$.

En consecuencia, el TJ cierra su pronunciamiento señalando que la petición de decisión prejudicial planteada por el TEAC es inadmisible, ya que no puede calificarse al organismo que la ha formulado como órgano jurisdiccional a efectos del art. 267 TFUE $^{44}$.

42 Art. 243 de la Ley General Tributaria, BOE n. ${ }^{\circ}$ 302, de 18 de diciembre de 2003.

43 Apdos. 76 y 77 de la sentencia.

44 Apdo. 80 de la sentencia. El abogado general es más tajante en sus conclusiones: «Considero que en el presente procedimiento no se debe seguir la sentencia de 21 de marzo de 2000, Gabalfrisa y otros» (punto 15 de las conclusiones). No obstante, el TJ advierte: «el hecho de que los TEA no tengan competencia prejudicial no les exime de la obligación de garantizar la aplicación del Derecho de la Unión al adoptar sus resoluciones e inaplicar, en su caso, las disposiciones nacionales que resulten contrarias a las disposiciones de Derecho de la Unión dotadas de efecto directo, ya que esa obligación recae sobre el conjunto de autoridades nacionales competentes y no solamente sobre las autoridades judiciales. Por otro lado, la existencia de recursos judiciales ante la $\mathrm{Au}$ diencia Nacional y el Tribunal Supremo contra las resoluciones que adoptan los TEA en el procedimiento económico-administrativo de reclamación permite garantizar la efectividad del mecanismo de remisión prejudicial previsto en el artículo 267 TFUE y la unidad de interpretación del Derecho de la Unión, dado que dichos órganos jurisdiccionales nacionales disponen de la facultad, o, en su caso, tienen la obligación, de plantear cuestiones prejudiciales al Tribunal de Justicia cuando para poder emitir su 
En definitiva, tal como señala Alonso García, tras advertir que el concepto de «independencia» comporta dos aspectos, uno de índole externa y otro de índole interna, el TJUE llega a la conclusión de que tales aspectos brillan por su ausencia en el caso del TEAC (2020). Como señalara Arrieta, la rectificación del $\mathrm{TJ}$ no puede extrañar a nadie, «a muchos, incluso, nos suena a solemne boutade» afirmar que no puede calificarse al TEAC de órgano jurisdiccional $(2020)^{45}$.

\section{LAS RAZONES DEL CAMBIO JURISPRUDENCIAL}

Tiene interés señalar que en el asunto Banco Santander, el TJ explica que aboga por la revisión de sus razonamientos «habida cuenta, en particular, de la jurisprudencia más reciente del Tribunal de Justicia ${ }^{46}$. En efecto, el TJ y el abogado general coinciden en señalar que la apreciación según la cual los TEA gozaban de suficientes garantías de independencia como para ser considerados un órgano jurisdiccional a los efectos del art. 267 TFUE ya no se puede seguir sosteniendo, sobre todo en vista de las consideraciones realizadas por el TJ en asuntos recientes ${ }^{47}$, respecto a los que la sentencia cita expresamente aquellos

fallo sea necesaria una decisión sobre la interpretación o sobre la validez del Derecho de la Unión» (apdos. 78 y 79 de la sentencia).

45 Para Juan Arrieta «la autonomía funcional de la que disfrutan (los TEA) no es sinónimo de independencia, dadas las normas de selección y nombramiento que tienen los vocales y presidentes de sala del TEAC y de los TEA, así como por la dependencia jerárquica y presupuestaria que existe respecto del Ministerio de Hacienda. Por no hablar de, entre otros, el recurso extraordinario para la unificación de doctrina, un recurso excepcional, pero que es enormemente indicativo del evidente control y dirección que persigue ejercer el Ministerio sobre los TEA. Como recuerda la sentencia del TJUE, se trata de un recurso que únicamente pueden interponer los Directores Generales de Tributos contra las decisiones que no les gustan del TEAC - «cuando esté en desacuerdo con el contenido de dichas resoluciones», dice el art. 243.1 LGT-, y un recurso que va a resolver una Sala especial conformada por el propio Director General de Tributos y otros Directores generales de la propia AEAT. Afortunadamente, pocas veces se ha utilizado este recurso, aunque siempre ha sido con un enorme eco respecto de su uso y respecto de la decisión adoptada. En fin, una absoluta anomalía procesal que ni el transcurso del tiempo la convierte en asumible».

46 Apdo. 55 de la sentencia.

47 Apdos. 56-59 de la sentencia y apartado 15 de las conclusiones. 
que dieron lugar a las sentencias Associaçao Sindical dos Juizes Portugueses ${ }^{48}$ (ASJP) y Comisión c. Polonia (Indépendance de la Cour suprême) ${ }^{49}$.

La referencia a estas sentencias no es fortuita. En efecto, el asunto ASJP ha permitido que el criterio de independencia alcance una nueva dimensión, vinculada al Estado de derecho ${ }^{50}$. En su sentencia de 27 de febrero de 2018, que da respuesta a las cuestiones prejudiciales planteadas por el Supremo Tribunal Administrativo de Portugal a raíz de las medidas de austeridad presupuestaria vinculadas a la ayuda financiera a Portugal, el TJ señaló que los órganos a los que se confía la responsabilidad de defender el Estado de derecho en la UE, es decir, los órganos jurisdiccionales en el sentido del art. 267 TFUE, deben cumplir los requisitos de la tutela judicial efectiva, lo que significa que deben ser independientes ${ }^{51}$. A juicio del tribunal, el órgano jurisdiccional debe ejercer sus funciones jurisdiccionales «con plena autonomía, sin estar sometido a ningún vínculo jerárquico o de subordinación respecto a terceros y sin recibir órdenes ni instrucciones de ningún tipo, cualquiera que sea su procedencia, de modo que quede protegido de injerencias o presiones externas que puedan hacer peligrar la independencia de sus miembros a la hora de juzgar o que puedan influir en sus decisiones ${ }^{52}$. La independencia, por tanto, no es una garantía solo relevante para los tribunales de la Unión, sino también para los tribunales nacionales ${ }^{53}$.

En palabras de Bonelli y Claes (2018: 623), Luxemburgo ha querido precisar que la organización de los poderes judiciales nacionales no es un asunto exclusivo de cada uno de los Estados miembros por separado, sino que los Estados miembros tienen una obligación, contenida en el derecho

48 Sentencia de 27 de febrero de 2018, C-64/16, EU:C:2018:117.

49 Sentencia de24 de junio de 2019, C-619/18, EU:C:2019:531.

50 Para Pech y Platon (2018: 1827), la sentencia ASJP es el asunto más importante desde Les Verts, en lo que respecta al significado y el alcance del principio del Estado de Derecho en el sistema jurídico de la UE. Para Paz Andrés y Daniel Sarmiento el criterio de independencia alcanza también una dimensión constitucional (Andrés Sáenz de Santa María, 2020; Sarmiento, 2018).

51 «Habida cuenta de que, de conformidad con la reiterada jurisprudencia [...] tal mecanismo únicamente puede activarlo un órgano que, con competencia para aplicar el Derecho de la Unión, se atenga, entre otros, al criterio de independencia» (apdo. 43 de la sentencia).

52 Apdo. 44 de la sentencia.

53 Apdo. 42 de la sentencia. Tal como señala Aida Torres (2020:105): «In Associação Sindical dos Juízes Portugueses, the CJEU seized the occasion to uphold the principle of judicial independence as a primary obligation for the Member States under the second subparagraph of Article 19(1) TEU». 
primario de la UE y supervisada por el Tribunal de Justicia para garantizar que sus tribunales y jueces sean independientes en los ámbitos cubiertos por la legislación de la UE. En caso contrario, según indica Lenaerts (2018: 7-8), a falta de independencia judicial el procedimiento prejudicial quedaría sin propósito. Se rompería un eslabón en la cadena de justicia europea y, como resultado, inevitablemente se debilitaría el Estado de derecho en el conjunto de Europa.

Tal como ha señalado Campos Sánchez-Bordona (2020: 14), el asunto $A S J P$ «se inserta en un trasfondo determinado y en un momento histórico en el que la independencia judicial estaba siendo objeto de ataques en algunos Estados miembros»; en este sentido, aunque algunos han visto esta sentencia como el puente que el TJ necesitaba para la defensa del Estado de derecho (Bonelli y Claes, 2018: 641; García-Valdecasas Dorrego, 2019: 86; Krajewski, 2018: 402 y Torres, 2020: 105-119) ${ }^{54}$, lo cierto es que este pronunciamiento también ha servido para consolidar la independencia del órgano judicial como requisito imprescindible para la atribución de competencia prejudicial: «La independencia de los órganos judiciales nacionales resulta esencial para el buen funcionamiento del sistema de cooperación judicial ínsito en el mecanismo de remisión prejudicial previsto en el artículo 267 TFUE» ${ }^{55}$. Como ya adelantara García-Valdecasas Dorrego (2010:86), «a la luz de las consideraciones realizadas en esta sentencia, el TJ podría negar la condición de órgano jurisdiccional a órganos administrativos a los que ya se les había reconocido dicha condición». La sentencia en el asunto Banco de Santander ha venido a confirmar este pronóstico.

A su vez, en la sentencia Comisión/Polonia (Independencia del Tribunal Surpremo ${ }^{56}$, que pone fin al segundo ${ }^{57}$ de los procedimientos por incumplimiento iniciados contra Polonia, a consecuencia de la adopción de una serie de normas que rebajaban la edad de jubilación de los jueces del Tribunal Supremo polaco y que permitían al presidente de la República de Polonia prorrogar discrecionalmente el mandato de esos mismos jueces, el TJ volvió a incidir en el aspecto externo de la independencia, en la equidistancia que

54 Parodi (2018: 990) señala que «la sentenza Associação Sindical dos Juízes Portugueses fornisce un interessante spunto di riflessione in relazione alla necessità di rafforzare il controllo del rispetto dello Stato di diritto da parte degli Stati membri attraverso il sistema giurisdizionale integrato dell'UE».

55 Apdo. 43 de la sentencia.

56 Sentencia de 24 de junio de 2019, ya citada.

57 El primer procedimiento interpuesto por la Comisión se resolvió cinco meses más tarde y dio lugar a la sentencia de 5 de noviembre de 2019, Comisión/Polonia (Independencia de las jurisdicciones de derecho común), C-192/18, EU:C:2019:924. 
debe guardar el órgano jurisdiccional con respecto a las partes del litigio y a sus intereses respectivos en relación con el objeto del litigio:

Estas garantías de independencia e imparcialidad postulan la existencia de reglas, especialmente en lo referente a la composición del órgano, así como al nombramiento, a la duración del mandato y a las causas de inhibición, recusación y cese de sus miembros, que permitan excluir toda duda legítima en el ánimo de los justiciables en lo que respecta a la impermeabilidad de dicho órgano frente a elementos externos y en lo que respecta a su neutralidad con respecto a los intereses en litigio ${ }^{58}$.

En palabras de Campos Sánchez-Bordona (2020: 20), el TJ pone especial énfasis «en la percepción de los justiciables: las reglas sobre el estatuto orgánico de los jueces han de permitir "excluir toda duda legítima en el ánimo de los justiciables en lo que respecta a la impermeabilidad [de los órganos judiciales] y a su neutralidad con respecto a los intereses en litigio"».

Al mismo tiempo, el TJ advierte que el principio de inamovilidad, aplicable a aquellos que tienen la misión de juzgar, solo puede ser objeto de excepciones cuando existan motivos legítimos e imperiosos que lo justifiquen y siempre que se respete el principio de proporcionalidad: «La necesidad de independencia exige que las normas que rigen el régimen disciplinario presenten las garantías necesarias para evitar cualquier riesgo de que dicho régimen pueda utilizarse como sistema de control político del contenido de las resoluciones judiciales" ${ }^{59}$.

Por tanto, la existencia de normas que definan qué comportamientos son constitutivos de infracciones disciplinarias o las sanciones que les son aplicables resultará esencial para determinar la independencia de un órgano judicial.

Más recientemente, el TJ ha vuelto a incidir en la importancia de la independencia judicial desde la perspectiva del Estado de derecho. En su sentencia de 26 de marzo de $2020^{60}$, que da respuesta a las cuestiones prejudiciales planteadas por el Sąd Okręgowy w Łodzi (Tribunal Regional de Łódź, Polonia) y por el Sąd Okręgowy w Warszawie (Tribunal Regional de Varsovia, Polonia), a propósito también de las modificaciones legislativas que afectan a la independencia de la judicatura polaca, el TJ ha señalado que la competencia prejudicial que se otorga a los órganos jurisdiccionales de la UE en exclusiva es inherente a su independencia. En consecuencia, los órganos

\footnotetext{
58 Apdo. 74 de la sentencia.

59 Apdo. 77 de la sentencia.

60 Miasto Łowicz, C-558/18 y C-563/18, EU:C:2020:234.
} 
jurisdiccionales no deben estar expuestos a procedimientos o sanciones disciplinarios por haber hecho uso de su competencia prejudicial ${ }^{61}$.

En la misma línea, mediante auto de 8 de abril de $2020^{62}$, el TJ ha estimado las medidas provisionales solicitadas por la Comisión en el marco del tercer procedimiento por incumplimiento iniciado contra Polonia para proteger a los jueces polacos del control político tras la reforma del régimen disciplinario del poder judicial. En su auto, el TJ ha vuelto a incidir en la obligación de los Estados miembros de respetar y mantener la independencia de sus órganos jurisdiccionales, también en lo que respecta a los procedimientos disciplinarios contra los propios jueces ${ }^{63}$. Esto significa que la legislación de la UE impide la creación de organismos disciplinarios que no cumplan las garantías inherentes a la protección judicial efectiva, incluida la independencia.

En definitiva, como ha apuntado Andrés Sáenz de Santa María (en prensa), desde la perspectiva del mecanismo de la cuestión prejudicial, estas decisiones vinculadas a la defensa del Estado de derecho en los Estados miembros han provocado un efecto colateral que tiene como consecuencia privar a algunos órganos del diálogo judicial con el TJUE que antes se les permitía. Ello sin perjuicio de que hubiera razones de fondo que permitieran cuestionar esa permisividad.

\section{LA LETRA PEQUEÑA DEL ASUNTO BANCO SANTANDER: LOS ÓRGANOS DE NATURALEZA ADMINISTRATIVA}

Tras la sentencia Banco Santander, las nuevas exigencias de independencia podrían poner en entredicho la competencia prejudicial de otros órganos jurisdiccionales. Seguramente para delimitar el alcance de su decisión, en la sentencia el TJ menciona al Tribunal Català de Contractes del Sector Públic (TCCSP) y al Klagenævnet for Udbud, órganos ambos responsables de los recursos en materia de adjudicación de contratos públicos, creados al amparo del art. 2, apdo. 9, de la Directiva 89/665.

El TCCSP es el órgano encargado de conocer los recursos especiales planteados contra las decisiones de adjudicación en materia de contratación pública en Cataluña. Es un órgano no perteneciente al poder judicial y de naturaleza administrativa al que el $\mathrm{TJ}$ reconoció competencia prejudicial en el

\footnotetext{
61 Apdos. 58 y 59 de la sentencia.

62 Comisión/Polonia, C-791/19, EU:C:2020:277.

63 Apdo. 77 del auto.
} 
asunto Consorci sanitari del Maresme ${ }^{64}$. Por su parte, el Klagenævnet for Udbud (Comisión de recursos en materia de contratación pública de Dinamarca) es un órgano creado para la supervisión de las licitaciones públicas danesas; el TJ admitió su primera remisión prejudicial en el año 1999, en el asunto Unitron Scandinavia ${ }^{65}$.

En el asunto Banco Santander, el TJ señala que la situación de los miembros de los tribunales económico administrativos, y en concreto del TEAR, es distinta a las de los miembros del TCCSP, que disfrutan «de una garantía de inamovilidad mientras dure su mandato, que solo admite excepciones por causas expresamente enumeradas por la ley ${ }^{66}$. El TJ no hace mención a su dependencia orgánica, se olvida de que el TCCSP está adscrito al Gobierno autonómico, la Generalitat de Catalunya, más en concreto a Presidencia ${ }^{67}$.

El Tribunal también reitera lo dispuesto en el asunto Unitron Scandinavia: la composición mixta del Klagenævnet for Udbud garantiza perfectamente su independencia. De modo que aunque entre sus miembros se incluya a expertos que no disfrutan de la protección particular que una disposición constitucional otorga a los magistrados, el hecho de que en su composición se integren magistrados que sí disfrutan de dicha protección y disponen en cualquier circunstancia de la mayoría de votos y, por tanto, de un peso preponderante en la toma de decisiones de dicho organismo es suficiente para garantizar la independencia del resto de miembros.

Pues bien, recordemos que en otros asuntos como Dorsch Consult y Köllensperger y Atzwanger ${ }^{68}$, el TJ también había flexibilizado la consideración de la condición de tercero del órgano jurisdiccional remitente, dejando al margen la ausencia de normas específicas destinadas a garantizar la independencia de sus miembros. En estos asuntos el TJ había admitido las cuestiones

64 Sentencia de 6 de octubre de 2015, ya citada. El TJ consideró que el TCCSP tenía la condición de tercero con respecto a la autoridad que adopta las decisiones recurridas ante él. Ello en base a que el TCCSP ejercía sus funciones con plena autonomía, sin estar sometido a ningún vínculo jerárquico o de subordinación y que sus miembros eran inamovibles y solo podían ser cesados por alguna de las causas expresamente enumeradas en la normativa que los regula (art. 8, apdo. 4, del Decreto 221/2013 de la Generalitat de Catalunya).

65 Sentencia de 18 de noviembre de 1999, Unitron Scandinavia y 3-S, C-275/98, EU:C:1999:567.

66 Apdo. 70 de la sentencia.

67 Arts. 1 y 2 del Decreto 221/2013 de la Generalitat de Catalunya.

68 Sentencia de 17 de septiembre de 1997, C-54/96, EU:C:1997:413 y Sentencia de 4 de febrero de 1999, C-103/97, EU:C:1999:52. 
prejudiciales planteadas por una comisión para el control de la adjudicación de contratos públicos, pese a que dependía orgánicamente del Ministerio de Economía y de una oficina de adjudicaciones, respecto a la cual la Administración del Estado ostentaba la potestad revocatoria de sus miembros.

Sin embargo, con esta mención expresa a estos dos órganos, quizá prescindible, el TJ parece querer evitar que la competencia prejudicial de los órganos responsables de los recursos en materia de adjudicación de contratos públicos pueda ser de nuevo verificada. Como ya hiciera entonces, el TJ vuelve a mostrar cierta flexibilidad en la evaluación de cada uno de los criterios para justificar una evaluación global de todos ellos. Así pues, parece que, por el momento, no podemos esperar que el nuevo canon de independencia sea aplicable a los tribunales administrativos de contratos públicos.

\section{EL PRÓXIMO ESCOLLO: LA COMISIÓN NACIONAL DE LOS MERCADOS Y LA COMPETENCIA}

En un futuro cercano, el TJ tendrá que volver a examinar la competencia prejudicial de la Comisión Nacional de los Mercados y la Competencia española (CNMC), sucesora del extinto Tribunal de Defensa de la Competencia (TDC). Conviene recordar que mediante auto de 28 de enero de 1991 ese Tribunal planteó, con arreglo al antiguo art. 177 TCEE, varias cuestiones prejudiciales sobre la interpretación del art. 214 del Tratado CEE y del Reglamento n. ${ }^{\circ} 17$ del Consejo, cuyo carácter jurisdiccional también fue muy cuestionado ${ }^{69}$.

El TDC, creado por la Ley $110 / 1963^{70}$, estaba dotado de los rasgos aparentemente necesarios para ser considerado como órgano jurisdiccional, esto es, origen legal, permanencia, jurisdicción obligatoria, procedimiento contradictorio y aplicación de normas jurídicas; sin embargo, pese a que en la misma ley también se indicaba que el TDC gozaría de plena y absoluta

69 Las cuestiones formuladas por el TDC se plantearon en el trascurso de un litigio que la Dirección General de Defensa de la Competencia había elevado al TDC para resolver un expediente abierto contra la Asociación Española de Banca Privada, el Banco Popular Español, el Banco Bilbao Vizcaya, el Banco Central, el Banco Español de Crédito y el Banco de Santander, por haber vulnerado ciertas disposiciones de la Ley 110/1963 de 20 de julio de Represión de Prácticas Restrictivas de la Competencia, relativas a determinados servicios y comisiones bancarias.

70 Ley 110/1963, de 20 de julio, de Represión de Prácticas Restrictivas de la Competencia, BOE n.o 175 , de 23 de julio de 1963, pp. 11144 a 11152, derogada por la Ley $16 / 1989$. 
independencia en su función, este aspecto fue cuestionado. Por un lado, porque su cometido principal consistía en imponer las sanciones que previamente le proponía la Dirección General de Defensa de la Competencia; por otro, porque la misma ley que lo creaba y la posterior Ley $16 / 1989^{71}$ lo adscribían orgánicamente al «Ministerio competente en razón de la materia»" es decir, al Ministerio de Economía y Hacienda, y, por último, porque sus acuerdos definitivos en materia de imposición de multas eran impugnables ante la jurisdicción contencioso-administrativa ${ }^{73}$, lo que para algunos autores vendría a demostrar su naturaleza administrativa y no jurisdiccional ${ }^{74}$.

A pesar de ello, el TJ dio respuesta a las cuestiones planteadas por el $\mathrm{TDC}^{75}$ sin entrar a examinar su carácter jurisdiccional. Sí lo hizo el abogado general Jacobs, quien en sus conclusiones ${ }^{76}$, basándose en el auto de remisión del TDC, concluyó que no le cabía duda de que el TDC debía ser considerado un órgano jurisdiccional a efectos del art. 177 ya que el TDC gozaba de competencia privativa en determinadas materias, con arreglo a la legislación española, ejercía sus funciones con total independencia y sus miembros eran inamovibles.

Sin embargo, diez años más tarde, en el conocido asunto Syfait, el TJ declaró la inadmisión de la cuestión prejudicial planteada por la Comisión de

71 Ley 16/1989, de 17 de julio, de Defensa de la Competencia, BOE n. ${ }^{\circ} 170$, de 18 de julio de 1989, vigente hasta el 1 de septiembre de 2007.

72 Art. 20 de la Ley 16/1989.

73 Art. 31 Ley 110/1963.

74 Para Jimeno Bulnes (1996: 219), pese a que el TDC ejerciera sus funciones con plena independencia y sometimiento al ordenamiento jurídico, su adscripción al ministerio conllevaba que hubiese que englobarlo dentro de los tribunales administrativos por ejercer, además, funciones administrativas que son susceptibles siempre de revisión judicial por la vía contencioso-administrativa. Por su parte, según Illescas Ortiz (2003: 699-708) serían la Constitución y la Ley Orgánica del Poder Judicial las que impedirían que el TDC pudiera ser conceptuado como un órgano del poder judicial y por tanto dotarle de capacidad para plantear cuestión prejudicial, mientras que para Garrigues (1964: 111) el TDC sería claramente un órgano administrativo y no «un órgano judicial, ni siquiera cuasi-judicial». Por contra, Martínez Lage (1993: 1-3) defendió su carácter jurisdiccional, entendiendo que, aunque el TDC se limitara a imponer las sanciones que le propone la Dirección General de Defensa de la Competencia, este hecho no mermaba el carácter contradictorio del procedimiento.

75 Sentencia de 16 de julio de 1992, Asociación Española de Banca Privada, C-67/91, EU:C:1992:330.

76 Conclusiones del abogado general Jacobs, Asociación Española de Banca Privada, C-67/91, EU:C:1992:256, puntos 10-12. 
Defensa de la Competencia griega ${ }^{77}$. En este caso, el TJ sí entró a examinar su carácter jurisdiccional y consideró que el Epitropi Antagonismou no actuaba de manera suficientemente independiente ni conocía de un procedimiento que concluyera con una decisión de carácter jurisdiccional que le otorgara el carácter de un órgano jurisdiccional en el sentido del art. 267 TFUE.

El TJ señaló que el Epitropi Antagonismou se hallaba bajo la tutela del ministro del Desarrollo y que una tutela de esta índole implica que el citado ministro se hallaba facultado para controlar la legalidad de las resoluciones del Epitropi Antagonismou. Por otro lado, el TJ destacó el hecho de que la revocación o la anulación del nombramiento de los miembros de la Comisión de Defensa de la Competencia griega no parecía estar sujeta a garantías especiales que pudieran obstaculizar eficazmente las intervenciones o presiones indebidas por parte del poder ejecutivo sobre los miembros del organismo. Sin embargo, además de a su falta de independencia, el TJ cerraba su pronunciamiento haciendo referencia al derecho de avocación que posee la Comisión Europea en materia de competencia ${ }^{78}$. El TJ concluyó que en los supuestos en los que la Comisión priva de sus atribuciones al Epitropi Antagonismou, el procedimiento incoado ante este no puede concluir con una decisión de carácter jurisdiccional ${ }^{79}$.

Todo ello se interpretó como un claro endurecimiento de los requisitos que un órgano nacional debe reunir para tener competencia prejudicial (Fenger y Broberg, 2013: 119). Wathelet (2014: 393) señaló que el resto de autoridades nacionales de la competencia también podrían ser cuestionadas, lo que podría limitar notablemente el número de cuestiones prejudiciales en materia de competencia.

Hasta el momento el TJ no había tenido ocasión de reexaminar la competencia prejudicial de nuestra autoridad de la competencia, pues no ha

Sentencia de 31 de mayo de 2005, Syfait y otros, C-53/03, EU:C:2005:333.

78 Tal como señalara Wathelet (2014: 393), esta característica es común a todas las autoridades de la competencia de los Estados miembros. El Epitropi Antagonismou y el resto de las autoridades de la competencia de los Estados miembros se hallan obligados a trabajar en estrecha colaboración con la Comisión de las Comunidades Europeas y pueden ser privados de sus atribuciones en virtud de una decisión de la Comisión, con arreglo al art. 11, apdo. 6, del Reglamento (CE) n. ${ }^{\circ}$ 1/2003 del Consejo, de 16 de diciembre de 2002, relativo a la aplicación de las normas sobre competencia previstas en los artículos 81 y 82 del Tratado (DO 2003, L 1, p. 1): «Las autoridades de la competencia de los Estados miembros quedarán privadas automáticamente de sus atribuciones cuando la Comisión inicie un procedimiento» (Sentencia de 31 de mayo de 2005, ya citada, apdo. 34).

79 Ibid., apdo. 36. 
sido hasta junio de 2019 cuando la CNMC ha realizado su primer planteamiento prejudicial ${ }^{80}$. En su «acuerdo» ${ }^{81}$ de remisión, la CNMC se adelanta y afronta todas estas cuestiones; tras señalar que cumple con cada uno de los requisitos Vaasen Göbbels, se centra especialmente en su independencia y en la sentencia Syfait ${ }^{82}$.

Respecto a su independencia, la CNMC se atribuye la condición de tercero con respecto a la autoridad administrativa que pueda estar sometida a su control y asegura ejercer sus funciones «con total respeto de la objetividad y de la imparcialidad». La CNMC afirma tener un mayor grado de independencia que su predecesora: «Entonces, el órgano de instrucción dependía del Ministerio correspondiente mientras que, en este momento, tanto la Dirección de Competencia como el Consejo de la CNMC son independientes de cualquier órgano de la administración».

En este sentido, cabe señalar que todos los miembros de la CNMC son nombrados por el Gobierno, mediante real decreto, a propuesta del ministro de Economía y Competitividad, entre personas de reconocido prestigio y competencia profesional en el ámbito de actuación de la Comisión. Sin embargo, previamente a su nombramiento se exige la comparecencia de la persona propuesta para el cargo ante la comisión correspondiente del Congreso de los Diputados ${ }^{83}$. Además, tal como señala la propia CNMC, sus miembros son inamovibles y «solo pueden ser cesados por alguna de las causas expresamente enumeradas en el art. 23 de la Ley 3/2013».

La CNMC cierra el análisis de su competencia prejudicial refiriéndose a la sentencia Syfait, advirtiendo que la resolución en su conjunto no le es aplicable. Para ello, vuelve a insistir en su independencia orgánica o en las garantías especiales de nombramiento de los miembros de su Consejo, añadiendo que sus resoluciones tienen carácter ejecutivo y vinculante, siendo únicamente recurribles ante la jurisdicción contencioso-administrativa.

Respecto al derecho de avocación a favor de la Comisión Europea, la CNMC señala que el derecho de avocación ya estaba presente en el Reglamento n. ${ }^{\circ} 17$, vigente cuando el TJ admitió a tramite la cuestión prejudicial

80 Asunto Asoport, C-462/19, pendiente de resolver.

81 Así denomina la propia CNMC al escrito de remisión.

82 «Acuerdo por el que se eleva cuestión prejudicial al Tribunal de Justicia de la Unión Europea al amparo del artículo 267 del Tratado de funcionamiento de la Unión Europea y se suspende el procedimiento sancionador», de 12 de junio de 2019, Expte. S/DC/0619/17, disponible en http://curia.europa.eu/juris/showPdf.jsf?text=\&docid=220006\&pageIndex $=0 \&$ doclang $=$ es \& mode $=1$ st \&dir $=$ \&occ $=$ first \& part $=1 \&$ cid $=3379708$.

83 Así lo dispone el art. 19 de la Ley 3/2013. 
remitida por el antiguo Tribunal de Defensa de la Competencia. Todo ello le lleva a concluir con rotundidad: «Si el TDC fue considerado independiente, con mayor razón debe realizarse esa valoración en la CNMC que cumple con todos los caracteres necesarios para ser considerado como órgano jurisdiccional».

Este es el escenario con el que se va a encontrar el TJ. En coherencia con el asunto Syfait, podría esperarse que el TJ adoptase una postura más estricta que en su sentencia Asociación Española de Banca Privada. Sin embargo, la nueva Ley $3 / 2014$, además de hacer especial hincapié en su independencia orgánica y funcional y en la independencia de sus miembros respecto a cualquier interés empresarial o comercial o instrucción externa, provenga de entidad pública o privada $^{84}$, garantiza la inamovilidad de sus miembros, mientras dure su mandato.

De hecho, la confirmación de la competencia prejudicial de los órganos responsables de los recursos en materia de adjudicación de contratos públicos podría abogar a su favor. Al igual que lo hiciera el art. 8, apdo. 4, del Decreto 221/2013 de la Generalidad de Cataluña, la Ley 3/2013 tasa las causas por las que los miembros de la CNMC pueden ser cesados, lo cual podría ser suficiente para demostrar que sus miembros se encuentran protegidos de recibir presiones externas, directas o indirectas, que puedan hacer dudar de su independencia.

Por otro lado, cabe señalar que en el asunto $U X^{85}$, todavía pendiente de resolver, como ya hiciera en otros asuntos ${ }^{86}$, la abogada general Kokott ha

84 El primer apartado de su art. 2 señala que la Comisión actúa, en el desarrollo de su actividad y para el cumplimiento de sus fines, con autonomía orgánica y funcional y plena independencia del Gobierno, de las administraciones públicas y de los agentes del mercado. Asimismo, está sometida al control parlamentario y judicial, a lo que el art. 3 añade que, en el desarrollo de su actividad y para el cumplimiento de sus fines, actuará con independencia de cualquier interés empresarial o comercial. Además, el segundo apartado de este mismo artículo advierte que ni el personal ni los miembros de los órganos de la Comisión Nacional de los Mercados y la Competencia podrán solicitar o aceptar instrucciones de ninguna entidad pública o privada.

85 C-658/18, pendiente de resolver.

86 En el asunto Margarit Panicello, la abogada general Kokott defendió la independencia de los antiguos secretarios judiciales españoles, actuales letrados de la administración de justicia. En sus conclusiones al caso Kokott señaló que existían varias premisas que aseguraban y demostraban la independencia externa de los secretarios judiciales, como son el hecho de que sean seleccionados a través de los sistemas de oposición o de concurso-oposición libre o el hecho de que los secretarios judiciales ostentasen el derecho individual al mantenimiento de su condición funcionarial sin ser removidos del puesto de trabajo que desempeñen sino solo en los supuestos y 
abogado por retomar una postura más flexible ${ }^{87}$. Al examinar la independencia de los jueces de paz italianos y en concreto su aspecto externo, ha señalado que «a semejanza de lo que sucede con la cuestión de la pertinencia de una petición de decisión prejudicial, el Tribunal de Justicia deberá presumir que los órganos jurisdiccionales de los Estados miembros gozan de una independencia objetiva suficiente» ${ }^{88}$. Ello en base a la "confianza mutua en los sistemas judiciales de los Estados miembros que el Tribunal de Justicia también debe asumir $^{89}$.

\section{CONSIDERACIONES FINALES}

En los últimos años el TJ ha incidido especialmente en que la independencia se torne en un principio compartido entre todos los órganos jurisdiccionales de la UE, esto es, entre los órganos judiciales de la UE y aquellos que forman parte de los ordenamientos estatales. Guiado por su afán de proteger la independencia judicial como elemento imprescindible del Estado derecho, parece que el TJ ha encontrado un nuevo camino en la determinación del concepto de órgano jurisdiccional.

La independencia judicial, directamente vinculada con el derecho a la tutela judicial efectiva, constituye un requisito esencial para garantizar la eficacia del sistema de cooperación judicial instaurado a través de la cuestión

condiciones establecidos legalmente. Por último, la abogada general consideró que la competencia que correspondía a los secretarios judiciales en la jura de cuentas no era objeto de delegación ni habilitación y destaca que en cada procedimiento los secretarios judiciales actuaban, exclusivamente, de conformidad con las competencias que les habían sido atribuidas sin estar sujetos a indicaciones, ya que la autoridad pública que los emplea no puede, en ningún caso, influir en procedimientos pendientes ni impartir instrucciones particulares relativas a asuntos concretos. Sin embargo, el TJ adoptó un criterio mucho más estricto determinando que el secretario judicial, en el ejercicio de sus funciones, debía atenerse a las instrucciones que le impartía su superior jerárquico salvo cuando ejercía las competencias relativas a la fe pública judicial, ya que «en el estado actual de la legislación española, el secretario judicial tramita el expediente de jura de cuentas [...] con observancia de los principios de unidad de actuación y dependencia jerárquica», no constituyendo un órgano jurisdiccional a efectos del artículo 267 TFUE y careciendo, por tanto, de facultad para plantear una cuestión prejudicial.

87 Conclusiones de la abogada general Juliane Kokott, UX, C-658/18, C-EU:C:2020:33.

88 Punto 46 de las conclusiones.

89 Ibid. 
prejudicial: el mecanismo prejudicial solo puede ser activado por un «órgano jurisdiccional» independiente.

La sentencia Banco Santander contribuye a consolidar el criterio de la independencia como el rasgo diferenciador de un órgano jurisdiccional nacional respecto a una autoridad administrativa: la independencia funcional y orgánica se erige ahora como el rasgo indispensable para poder ser titular de la competencia prejudicial.

Con todo, el asunto Banco Santander nos vuelve a mostrar algunas sombras, pues la esperada revisión de la competencia prejudicial de los tribunales económico administrativos se ve empañada por la prescindible confirmación de la competencia prejudicial de los órganos encargados de conocer los recursos contra la adjudicación de contratos públicos, lo cual no sirve más que para alimentar las voces que califican su jurisprudencia de casuística y poco clara. El TJ podría haber aprovechado la ocasión para negar la condición de órgano jurisdiccional a aquellos órganos administrativos que no son estrictamente jurisdiccionales y que no cumplen con alguno de los dos aspectos que comporta el concepto de independencia.

En los próximos meses el TJ tendrá ocasión de reexaminar la competencia prejudicial de otro órgano parajudicial, la Comisión Nacional de los Mercados y la Competencia española. Con ello el TJ deberá optar entre seguir desarrollando su línea jurisprudencial relativa a las exigencias de independencia judicial o por retroceder hacia un criterio más flexible, basado en la evaluación global de los requisitos Vaasen Göbbels. En cualquier caso, seguirá nutriendo esta dimensión tan dinámica de su jurisprudencia.

\section{Bibliografía}

Alonso García, R. (2020). Los Tribunales económico-administrativos dejan de estar habilitados por el TJUE para plantearle cuestiones prejudiciales: sus consecuencias internas. Almacén de Derecho [blog], 29-1-2020. Disponible en: https://bit. ly/2YD9oy3.

- (2011). La noción de órgano jurisdiccional a los efectos de activar la cuestión prejudicial. En C. F. Fernández Liesa, C. J. Moreiro González, E. Menéndez Rexach (dirs.). Homenaje a Dámaso Ruiz-Jarabo Colomer (pp. 147-165). Madrid: Consejo General del Poder Judicial.

Andrés Sáenz de Santa María, P. (en prensa). Rule of law and judicial independence in the light of CJEU and ECtHR case law. En C. Izquierdo Sans, C. Martínez Capdevila y M. Nogueira Guastavino (eds.). Fundamental Rights Challenges - Horizontal Effectiveness, Rule of Law and Margin of National Appreciation. Cham (Switzerland): Springer. 
Arrieta, J. (2020). El TJUE descubre que los tribunales económico-administrativos no son tribunales independientes. Blog de la Facultad de Derecho [blog], 27-22020. Disponible en: https://bit.ly/2C45d6y.

Banacloche Pérez-Roldán, J. (2001). Los Tribunales Económico-Administrativos. Impuestos. Revista de doctrina. Legislación y Jurisprudencia, 1, 83-90.

Biavati, P. (2005). Diritto processuale dell'Unione Europea. Milano: Giuffrè Editore.

Bonelli, M. y Claes, M. (2018) Judicial serendipity: how Portuguese judges came to the rescue of the Polish judiciary. European Constitutional Law Review, 14 (3), 622-643. Disponible en: https://doi.org/10.1017/S1574019618000330.

Campos Sánchez-Bordona, M. (2020). La protección de la independencia judicial en el derecho de la Unión Europea. Revista de Derecho Comunitario Europeo, 65, 11-31. Disponible en: https://doi.org/10.18042/cepc/rdce.65.01.

Cienfuegos Mateo, M. (2005). La noción de órgano jurisdiccional de un Estado miembro ex artículo 234 del tratado CE y su necesaria revisión. Gaceta Jurídica de la UE y de la Competencia, 238, 3-26.

- (2014). Noción de órgano jurisdiccional a los efectos de plantear una cuestión prejudicial. En R. Alonso García, J. I. Ugartemendía Eceizabarrena (dirs.). La cuestión prejudicial europea (pp. 28-43). Oñati: Instituto Vasco de Administración Pública.

Concellón Fernández, P. (2017). Tribunal de Justicia de la Unión Europea - De nuevo sobre el concepto de órgano jurisdiccional a efectos del artículo 267 TFUE: los secretarios judiciales y el expediente de jura de cuentas. Comentario de la sentencia TJUE de 16 de febrero de 2017, C-503/15, Margarit Panicello. Revista de Derecho Comunitario Europeo, 57, 709-733. Disponible en: https:// doi.org/10.18042/cepc/rdce.57.10.

- (2020). Los Órganos Jurisdiccionales Españoles y la Cuestión Prejudicial. Valencia: Tirant lo Blanch.

Condinanzi, M. y Mastroiannni, R. (2009). Il Contenzioso dell'Unione Europea. Torino: G. Giappichelli Editore.

Fenger, N. y Broberg, M. (2013). Le renvoi préjudiciel à la Cour de Justice de l'Union Européenne. Bruxelles: Larcier.

García de Enterría, E (1986). Las competencias y el funcionamiento del Tribunal de Justicia de las Comunidades Europeas. Estudio Analítico de los recursos. En E. García de Enterría, J. D. González Campos y S. Muñoz Machado. Tratado de Derecho Comunitario europeo. Estudio sistemático desde el Derecho español, Tomo I (p. 707). Madrid: Civitas.

García-Valdecasas Dorrego, M. J. (2019). El Tribunal de Justicia, centinela de la independencia judicial desde la Sentencia Associação Sindical dos Juízes Portugueses (ASJP). Revista Española de Derecho Europeo, 72, 75-96.

Garrigues, J. (1964). La defensa de la competencia mercantil. Madrid: Servicio de Estudios y Publicaciones.

Ibáñez García, I. (2011). Tres notas de actualidad sobre la Cuestión Prejudicial. Diario la Ley, 7591. 
Illescas Ortiz, R. (2003). Derecho de competencia: la competencia leal. En G. J. Jiménez Sánchez (coord..). Derecho Mercantil, Vol. 1 (pp. 699-708). Barcelona: Ariel.

Jimeno Bulnes, M. (1996). La cuestión prejudicial del artículo 177 TCE. Barcelona: Bosch.

Krajewski, M. (2018). Associação Sindical dos Juízes Portugueses. The Court of Justice and Athena's Dilemma. European Papers, 3 (1), 395-407.

Lenaerts, K., (2018). The Court of Justice and National Courts: A Dialogue Based on Mutual Trust and Judicial Independence. Discurso no Supremo Tribunal Administrativo de República da Polónia, Varsóvia. Disponible en: https://bit.ly/3d6HRKD.

Lenaerts, K., Arts, D., y Maselis, I. (2014). Procedural law of the European Union. London: Thomson.

Martín Ríos, P. (2020). Independencia judicial y responsabilidad disciplinaria judicial: especial mención a las "diligencias informativas". Revista Española de Derecho Constitucional, 118, 77-108. Disponible en: https://doi.org/10.18042/ cepc/redc. 118.03 .

Martínez Lage, S. (1993). Las cuestiones prejudiciales comunitarias en España. Gaceta Jurídica de la C. E., 86, 1-3.

Oliver, P. (2001). La recevabilité des questions préjudicielles: La jurisprudence des années 1990. Cahiers de droit européen, 37, 15-44.

Parodi, M. (2018). Il controllo della Corte di giustizia sul rispetto del principio dello Stato di diritto da parte degli Stati membri alcune riflessioni in margine alla sentenza Associação Sindical dos Juízes Portugueses. European Papers, 3 (2), 985-992.

Pech, L. y Platon, S. (2018). Judicial independence under threat: The Court of Justice to the rescue in the ASJP case. Common Market Law Review, 55 (6), 1827-1854.

Pérez Alonso, J. (2018). La independencia del Poder Judicial en la historia constitucional española. Historia constitucional: Revista Electrónica de Historia Constitucional, 19, 47-87. Disponible en: https://doi.org/10.17811/hc.v0i19.534.

Ruiz-Jarabo Colomer, D. (1993). El Juez nacional como Juez Comunitario. Madrid: Tecnos.

Sarmiento, D. (2018). On Constitutional Mode. Despite our Differences [blog], 6-3-2018. Disponible en: https://bit.ly/2UPCMzT.

Simon, D. (1998). Le système juridique communautaire. Paris: Presses Universitaires de France.

Soca Torres, I. (2016). La cuestión prejudicial europea. Planteamiento y competencia del Tribunal de Justicia. Barcelona: Bosch. Disponible en: https://doi. org/10.2307/j.ctvrzgxfm.

Soriano García, J. E. (1989). El efecto directo de las Directivas: posiciones iniciales de nuestra jurisprudencia. Noticias CEE, 52, 149-154.

Sosa Wagner, F. (2016). La independencia del juez, ¿una fábula? Un relato escrito para personas curiosas y legas. Madrid: La Esfera de los Libros. 
Torres, A. (2020). From Portugal to Poland. The Court of Justice of the European Union as watchdog of judicial independence. Maastricht Journal of European and Comparative Law, 27 (1), 105-119. Disponible en: https:/doi. org/10.1177/1023263X19892185.

Tridimas, T. (2003). Knocking on Heaven's Door: Fragmentation, Efficiency and Defiance in the Preliminary Reference Procedure. Common Market Law Review, 40, 9-27.

Wathelet, M. (2014). Contentieux européen. Bruxelles: Larcier. 